\title{
Economic implications of the Comprehensive and Progressive Agreement for Trans-Pacific Partnership (CPTPP) on Pakistan: a CGE approach
}

\author{
Muhammad Aamir Khan ${ }^{1,2^{*}}$, Naseeb Zada ${ }^{3}$ and Kakali Mukhopadhyay ${ }^{4,5}$
}

\section{${ }^{*}$ Correspondence:}

m.aamir.khan@comsats.

edu.pk

${ }^{1}$ Department of Economics,

COMSATS Institute

of Information Technology

(CIIT), Islamabad, Pakistan

Full list of author information

is available at the end of the

article

\begin{abstract}
The Comprehensive and Progressive Agreement for Trans-Pacific Partnership (CPTPP) is one of the recently negotiated multilateral free trade agreements which aims to establish a free trade agreement between 11 economies (after US exit) on both sides of the Pacific. The formation and implementation of this proposed partnership is a valid threat for other economies, particularly for Pakistan. Pakistan will likely to suffer from this agreement due to trade diversion of textile and apparels in favor of the CPTPP members. The reason can be extended in terms of the likely'yarn forward rule,' according to which, it is obligatory for the CPTPP member economies to import all the components of manufactured products from other CPTPP member economies. So, the implementation of the CPTPP will have an impact on global supply chain of textile and apparels. With this backdrop, this study evaluates the likely impacts of the CPTPP on the regional trade flows and other macroeconomic aggregates of Pakistan using a global computable general equilibrium model. The economy-wide results show the proposed CPTPP will have a negative impact on Pakistan's real GDP, sectoral exports and imports and at household level. However, if Pakistan joins CPTPP, there is an overall positive impact on Pakistan's economy. Thus, keeping in view Pakistan's ideal geographical and strategic location and its potential to be a transit economy with a junction of south Asia, west Asia and central Asia, this study suggests that Pakistan's proposed entry to CPTPP will not only yield a wide gain to the region but will reduce the gap between poor and rich in Pakistan and hence will have a positive impact on overall income inequality in Pakistan.
\end{abstract}

Keywords: Trans-Pacific partnership, Growth, Inequality, Economy-wide framework JEL Classification: C53, E64, F10, F60, 138

\section{Introduction}

The successful performance of multilateral free trade agreements, such as Association of South East Asian nations (ASEAN), North Free Trade Agreement (NAFTA) and the European Union (EU) coupled with the failure of the Doha Development Round (DDR), has inspired other economies to integrate their economies with rest of the world through the instrument of trade liberalization under the large world integrations. This strategy led to the establishment of various regional integrations such as the Comprehensive and Progressive Agreement for Trans-Pacific Partnership (CPTPP) and Regional 
Comprehensive Economic Partnership (RCEP). CPTPP is a proposed agreement being negotiated between the economies of the Asia-Pacific region. It is an expansion of the existing free trade agreement between Brunei, Chile, New Zealand and Singapore. Currently CPTPP is negotiated between 11 economies including the existing four economies plus Australia, Canada, Japan, Malaysia, Mexico, Peru and Vietnam.

The economic objective of CPTPP (formerly named as TPP) is to create a platform of a deep economic integration and comprehensive free trade agreement. ${ }^{1}$ Through CPTPP, participating countries seek to liberalize and establish new rules and disciplines in the region beyond those that already exist in the WTO (Fergusson et al. 2015). Banga (2014) points out that CPTPP would be beyond the existing trade agreements in the Asia-Pacific region with a vast coverage of new ideas, investments, services, financial services, competition, government procurement, labor, intellectual property, environment, etc. Cheong and Tongzon (2013) argues that CPTPP is a mega trade agreement. Therefore, the foremost objective should be its economic value and should be open for other economies fulfilling the preliminary requirements. CPTPP itself is a deep and targeting economic integration with provisions that range from goods, services and investment to critical new issues such as the digital economy, intellectual property rights, regulatory coherence, labor and the environment (Petri and Plummer 2016). Due to the US' withdrawal, CPTPP may not be more effective and is no more threat to China. However, it is still a threat to the East Asian integration. It will attract some of the ASEAN economies that have various partnerships with China.

\subsection{Pakistan and the Comprehensive and Progressive Agreement for Trans-Pacific Partnership (CPTPP)}

Pakistan is not a part of the proposed CPTPP which might yield losses due to the trade diversion. The potential loss can be attributed to a yarn forward rule (YFR), according to which, it is obligatory for all the CPTPP members to acquire the components of manufacturing products from other CPTPP member economies. Thus, YFR will induce garment manufacturers in the CPTPP countries to source their inputs from CPTPP countries at the cost of non-CPTPP countries. This will be a clear case of trade diversion for non-СРТPP countries like Pakistan, India and China, i.e., moving trade away from more efficient producers to less efficient producers. This will most likely to disrupt regional and global supply chain in textile and clothing.

It is pertinent to mention here that textile and clothing sector accounts for roughly 8.5 percent of Pakistan's GDP, 45\% of its total labor force and provides livelihood support to 10-15 million people directly or indirectly (GoP, 2016). USA is one of the biggest export destinations of Pakistan with export share of 15\%. However, CPTPP even with US exit is still significant for Pakistan's bilateral trade flows. The share of Pakistan exports to CPTPP in 2014 is 6\%. The share of TPP in total Pakistan's imports is, however, relatively more considerable as compared to exports, i.e., share of TPP in total Pakistan's import is $11 \%$ in 2014. Figure 1 illustrates trend in the growth of Pakistan's bilateral trade with CPTPP.

The above discussion implies that Pakistan has significant trade links with the CPTPP economies and therefore it may face losses due to the possible trade diversion from СРTPP.

\footnotetext{
${ }^{1}$ https://en.wikipedia.org/wiki/Trans-Pacific_Partnership.
} 


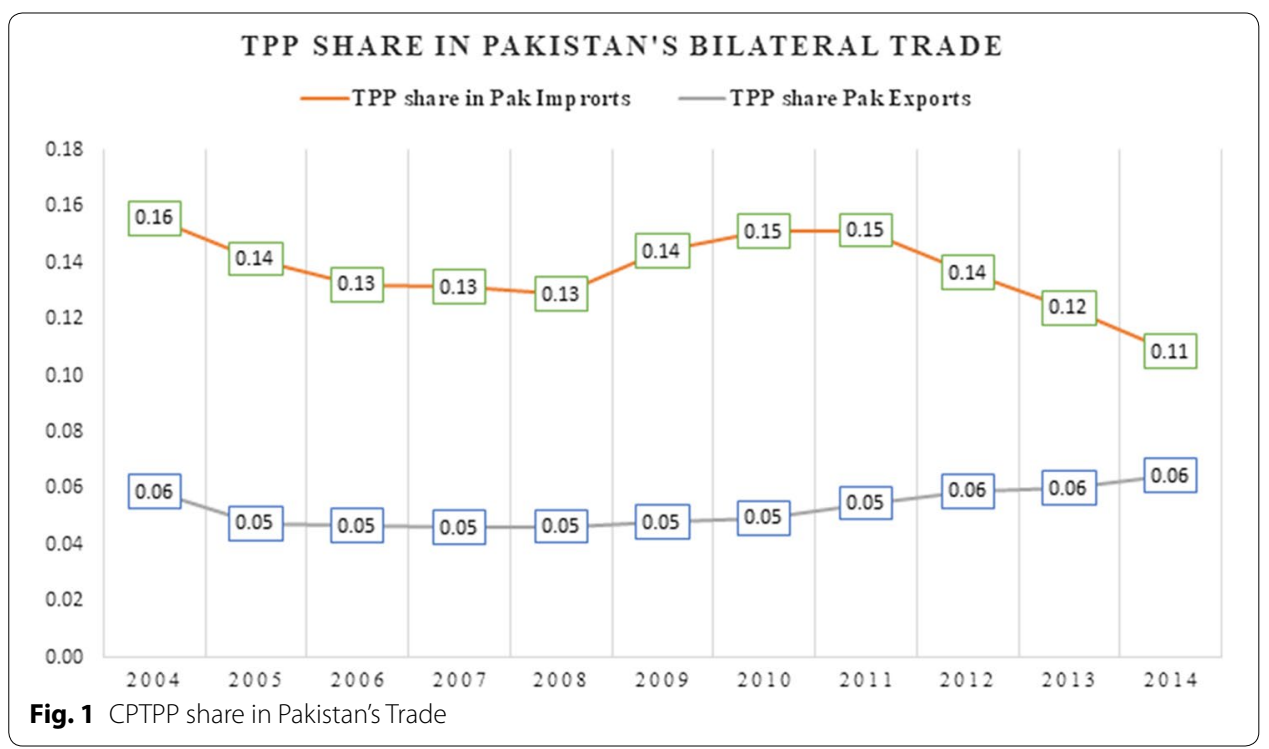

\subsection{Review of studies on TPP}

A large number of studies have identified the impact on non-members of CPTPP especially on small developing economies which are excluded from CPTPP. For instance, studies of Rahman and Ara (2015) consider the impact on Nepal and Bangladesh, Ganesh-Kumar and Chatterjee (2016) and Narayanan and Sharma (2016) for India, Cororaton and Orden (2015) for Philippines, Durongkaveroj (2015) for Thailand, Li and Yao (2014) and Lu (2015) for China, Oduncu et al. (2014) for Turkey and Thorstensen and Ferraz (2014) for Brazil. The potential impact of TPP on various economies in the framework of the CGE model is summarized in Table 1.

Above discussion on the literature shows that CPTPP has a worldwide impact. The impact on most of the CPTPP members is positive, but the literature also illustrates high welfare losses to most of the non-CPTPP members, such as Pakistan, Turkey, India and China. However, there is no significant study conducted to address the possible economic implication of CPTPP on Pakistan economy. Against this backdrop, the current study is carried out to evaluate the possible impact of CPTPP on the economy of Pakistan.

\section{Model and methodology}

In this study, we examine the potential impact of various scenarios of CPTPP on the economy of Pakistan in the computable general equilibrium (CGE) model framework which is briefly discussed in the following section.

\subsection{Computable general equilibrium (CGE) model}

Computable general equilibrium (CGE) model is an economic model, which is employed for the analysis of changes in government policies, technology and environment using real economic data. It is a multi-sectoral model and explains the explicit information about the behavior of economic agent. It treats households as utility maximizing agents and firms as cost-minimizing and profit-maximizing agents in the economy. It is assumed that agents' decisions about the production and consumption are based 


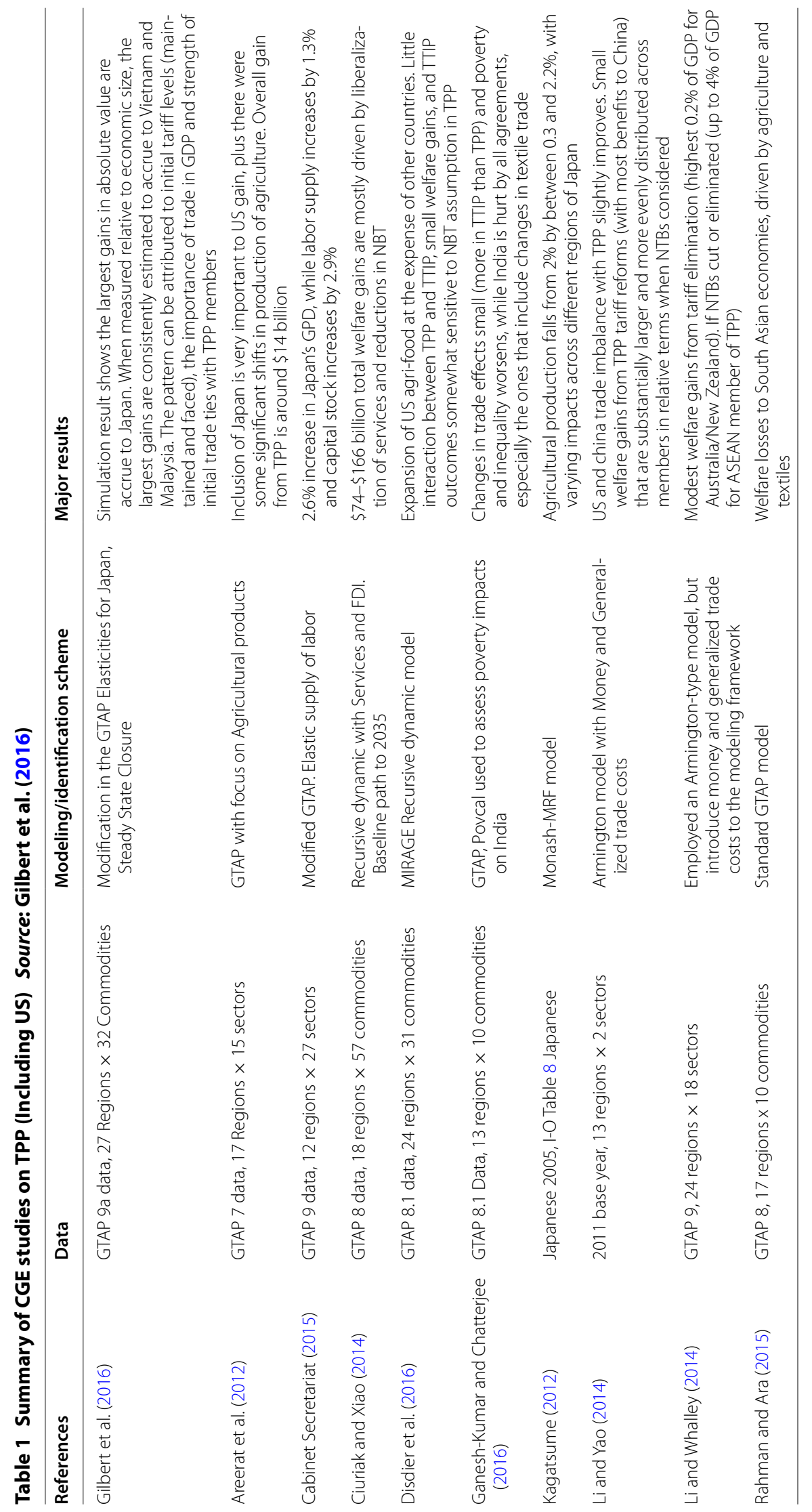




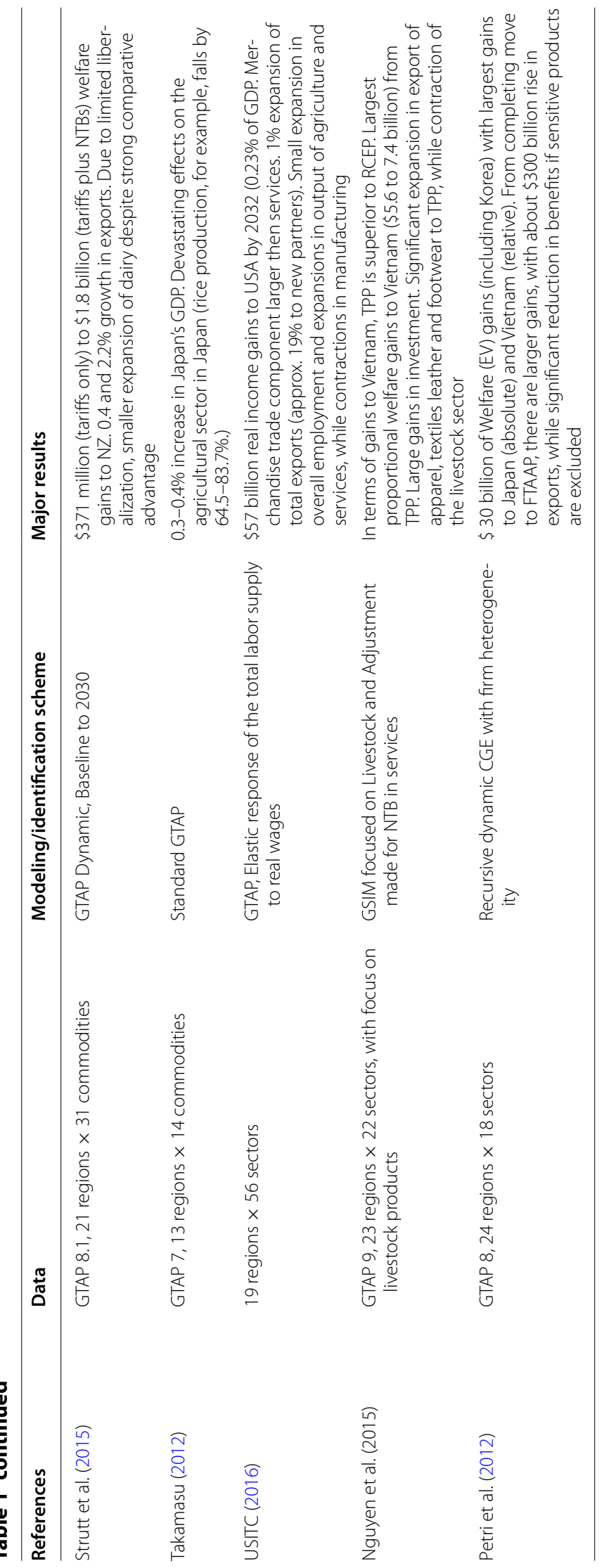


on prices, which are determined by the equilibrium conditions of demand and supply. Savard (2003) argues that the CGE model is a widely used and a suitable tool in the analysis of welfare, particularly poverty and inequality. In contrast to this, economic theory is abstract that cannot provide detailed analysis of the government policy reforms and is inadequate since it cannot account for the distributional impacts across sectors and households as shown by Winters et al. (2004) and Harrison et al. (2010). Bandara (1991) shows that CGE model is based on system of equations linking different sectors of the economy and the system is solved through various computer packages (GAMS, GEMPACK, MATLAB). Blake (1998) shows that the model is neoclassical in nature in which the producers follow the cost minimization and average pricing behavior and the households follow the optimization behavior. Adam et al. (1998) shows that the CGE model has two distinctive features; first, it incorporates a number of distinct sectors, and secondly, the model is characterized with a number of behavioral equations that deal with the response of industries and consumers against changes in relative prices. Shaikh et al. (2012) shows that the CGE or AGE models are internally consistent and are capable of capturing the economy-wide interactions as well as the inter-linkages between sectors. The models are particularly useful for analyzing the impact of changes in trade policy and allows for interactions among many endogenous variables simultaneously. They can, as such, correctly conclude the economy-wide impacts of changes in government policy reforms. In particular, CGE models are abstraction, complex and are able to capture the inter-linkages between different sectors in the economy as well as between different economies (Kehoe and Kehoe (1994)). Contrary to this, partial equilibrium analysis deals with only few endogenous variables and is mostly based on past time series data.

The CGE model in its global version also operates in the similar fashion, and its advantage over the simple CGE model is that it can account for the inter-linkages between economies. The global version of the CGE model is supported by the GTAP model that provides modeling framework and the database for the implementation of the CGE model. That is, the main source of data for the multi-country CGE model is the GTAP database which is briefly discussed in the following section.

The global trade analysis project (GTAP) is a global network between researchers and policy makers. Its centerpiece is the GTAP database that records the annual flows of goods and services with a given base year. The database is consistent in the sense that the data are internally consistent and employed to simulate the impact of changes in individual countries specific and also group-wise policies at the international level. GTAP model is a multi-region CGE model, which is designed to deal with the comparative static analysis of trade policy reforms (Adam et al. 1997). According to McDougall (1995), GTAP model is multi-sectoral and multi-regional model in nature. Therefore, it is tailor-made for analyzing the trade policy reforms.

\subsection{Global trade analysis project (GTAP)}

GTAP model is governed with a single regional household and an aggregate utility function. It allocates the regional expenditure across three components (private expenditure, the government expenditure and savings). The model assumes that the regional household sells its endowment commodities to the domestic firms and earns income. The firms, in turn, combine these endowment commodities with intermediate commodities 
and produce goods for final demand. The goods are purchased by private households and also the government households. Some of the goods such as capital goods and raw material are purchased by private households in order to satisfy their demand for savings. GTAP model in the open economy version incorporates two global sectors. The one is a global bank that works as intermediary between global savings and regional investment. The other sector is the trade accounts and transports activities. ${ }^{2}$ In this research, we used an extended version of GTAP known as MyGTAP model (Walmsley and Minor 2013).

\subsection{MyGTAP model}

The MyGTAP model removes the single regional household of the standard GTAP model. It introduces a separate government and multiple private households. The government household has separate income and expenditure accounts. There are two sources of the income of the government, i.e., taxes and foreign aid. It exhausts its income into expenditure on goods and services, and the rest is saved-also called government savings. The model identifies various sources of private households' income. These include factors' earnings, foreign remittances and capital income. Private household spends income on goods and services according to either constant difference expenditure (CDE) specification or linear expenditure system (LES) specification of the expenditure function. According to Walmsley and Minor (2013), MyGTAP model has several distinctions over the GTAP model. These include allowing (a): more flexibility in the treatment of government savings and expenditure, (b): the inter-regional transfers, i.e., remittances and capital income, and (c): tailor made tool to study the impact of a policy shock on different types of households and factors within the framework of the global CGE model.

\subsection{Dataset}

Two different types of datasets are used in this study: the recently released 'GTAP database 9a (Aguiar et al. 2016) and the latest comprehensive Pakistani SAM 2010-11(IFPRI, 2015). The GTAP database 9a represents the world economy for three reference years (2004, 2007 and 2011). We use the latest base year, i.e., 2011. The database is composed of 140 regions, 119 countries and 21 aggregated regions and 57 sectors for every region. To facilitate computation, the 140 regions are grouped into 30 regions ('Appendix 1') and the 57 commodity sectors into 15 highly aggregated sectors ('Appendix 2').

The Pakistani SAM 2010-11 provides detailed information on 16 types of household ('Appendix 4') classified by geographical zones and rural and urban categories. The SAM 2010-11 has 16 types of household as provided ('Appendix 4'). Household types are split by ownership of land and size of owned land. On the income side, information on the 12 factors of production ('Appendix 3') from the Pakistani SAM 2010-11 is disaggregated with the standard 5 GTAP production factors. The MyGTAP data program (Walmsley and Minor 2013) uses consumption and ownership weights obtained from the Pakistan SAM to disaggregate household income and consumption, and factor use and weights

\footnotetext{
2 The global bank creates a composite investment good and then supplies this to the regional households to satisfy their saving demands based on a common price for all the savers.
} 
Table 2 Simulation used in this study

\begin{tabular}{ll}
\hline Simulations & Description \\
\hline SIM-I & Full trade liberalization between CPTPP [11] economies and its impact on \\
& Pakistan \\
SIM-II & Full Trade Liberalization between CPTPP [11] + Pakistan \\
SIM-III & Full trade liberalization between CPTPP [11] economies + USA + Pakistan \\
\hline
\end{tabular}

are also obtained for the Pakistan SAM to disaggregate factors. These weights are applied to the GTAP database such that the total returns to factors and consumption are consistent with the original GTAP database.

\subsection{Income inequality estimation}

Inequality in general is termed as the dispersion of the distribution of income or some other welfare indicator (Litchfield 1999). This study used most commonly used measure of income inequality known as Gini coefficient to see the possible impact of TransPacific Trade Partnership on income inequality in Pakistan.

\subsubsection{Gini coefficient of inequality}

Gini coefficient is the most commonly used measure of inequality. The base of the Gini coefficient is a cumulative frequency curve-Lorenz curve-that compares the distribution of a specific variable (e.g., income, expenditure) with the uniform distribution that represents equality. The coefficient value ranges between 0 and 1 . We can state the Gini coefficient as:

$$
\text { Gini }=\frac{2}{n^{2} \bar{y}} \sum_{i=0}^{n} i\left(y_{i}-\bar{y}\right)
$$

\subsection{Research scenarios/simulation}

Three alternative scenarios are investigated to examine the economy-wide impact of CPTPP on Pakistani economy:

1. Current CPTPP (11): Business as usual, CPTPP with full trade liberalization among 11 CPTPP members and its implication on Pakistan Economy.

2. Current CPTPP (11) + Pakistan: Full trade liberalization between CPTPP (11) and Pakistan's proposed entry to CPTPP.

3. Current CPTPP (11) + Pakistan + USA: Full trade liberalization between CPTPP + USA + Pakistan.

The above simulation is summarized in Table 2.

We assume that CPTPP involves the complete removal of all tariffs between CPTPP partner countries while no accommodation is made for NTMs.

\subsection{Model closure}

The standard MyGTAP closures are taken as the starting point for our analysis. This assumes that there is perfect competition (zero economic profits) in all sectors. 
Production factor capital and labor are assumed to be fully mobile between sectors, whereas land and natural resource factors are sluggish to move. Government spending is assumed to be a constant share of government income, and there is no tax replacement; hence, as tariff revenue falls, the government deficit expands. Foreign income flows are assumed to rise or fall with factor prices in the country in which they are located. Investment is driven by the expected rate of return as in standard GTAP and total domestic savings by the sum of private household savings and the government budget deficit. Hence, the trade balance is endogenous.

\section{Results and discussion}

The results of the above-mentioned simulations are discussed in the following subsections.

\subsection{Impact of CPTPP on macroeconomic aggregates of Pakistan}

Table 3 illustrates the impact of various scenarios of CPTPP on the economy of Pakistan. Simulation 1 show a decrease in all macroeconomic aggregates of Pakistan.

Pakistan's overall terms of trade show deterioration by $0.17 \%$. Pakistan may also face decrease in real GDP along with decrease in real imports $(-0.23 \%)$ and exports ( $-0.03 \%)$. These results validate the critical concerns about CPTPP, according to which СРТPP may lead to trade diversion from the non-CPTPP members, which in turn may lead to economy-wide losses. We observe a significant increase in all macroeconomic aggregates of Pakistan due to extended CPTPP [CPTPP (11) + Pakistan]. Highest increase is shown by real exports (24.29\%), followed by real imports that show $10.94 \%$ increase. Pakistan's entry to CPTPP would also lead to a $5.30 \%$ increase in real investment. However, Pakistan might suffer due to deteriorating terms of trade by $1.52 \%$. The possible reason is the decrease in relative prices of exports due to Pakistan's entry to CPTPP, which may lead to deterioration in the terms of trade against other economies. According to the simulation III, most of the CPTPP members and even Pakistan will gain more if USA rejoins TPP. Pakistan real exports would boost by $27 \%$, which in turn would have a positive impact on real GDP and real investment, as evident from the simulation results. Adding to that, the terms of trade impact are likely to be improved in simulation III, which illustrates that CPTPP with USA, price received by Pakistani exports, will be more than the imports compared to CPTPP without USA.

Table 3 Impact of TPP on macroeconomic variables of Pakistan Source: Author's simulation

\begin{tabular}{llcc}
\hline & SIM-1 [CPTPP & $\begin{array}{l}\text { SIM-II [CPTPP (11) + Paki- } \\
\text { stan] }\end{array}$ & $\begin{array}{l}\text { SIM-III [CPTPP (11) + Paki- } \\
\text { stan + USA] }\end{array}$ \\
\hline Real GDP (qgdp) & -0.01 & 0.24 & 0.29 \\
Real investment & -0.56 & 5.30 & 6.74 \\
Terms of trade (TOT) & -0.17 & -1.52 & -0.30 \\
Real exports (qxwreg) & -0.03 & 24.29 & 27.0 \\
Real imports (qiwreg) & -0.23 & 10.94 & 14.35 \\
\hline
\end{tabular}




\subsection{Impact of CPTPP on sectoral output Pakistan}

Table 4 reveals the impact of various simulations on sectoral output of Pakistan. Simulation I shows a decrease in the production of Pakistan top tradable goods (textile, WAP and leather), while other notable sectors, which show a decline in production, include 'grain crops,' 'meat and livestock' and 'processed food.'

On the other hand, production of manufactures and extraction increases. The possible reason may be that Pakistan's non-participation in CPTPP may lead to decrease in sectorial imports. This would lead to increase in reliance on domestic production, thereby encouraging the production of import substitute sectors. Simulation II shows a positive and modest of textile (12.4\%) and wearing apparel (7.5\%), respectively. This indicates that CPTPP may encourage exports of these sectors, thereby leading to increase in the production of these top exportable commodities. Production of leather, light manufactures and 'meat and livestock' may decrease if Pakistan becomes a part of the CPTPP. Possible reason may be that Pakistan's entry to CPTPP may lead to increase in imports of these commodities, which may in turn discourage domestic production of import substitutes as these commodities are included in the list of Pakistan's top imports. Simulation III shows an increase in the production of Pakistan's main exportable items.

\subsection{Impact of CPTPP on sectoral exports of Pakistan}

Table 5 reports the impact of various simulations on sectoral exports of Pakistan. There is a negative impact on exports of wearing apparels $(-0.35 \%)$, textile $(-0.08 \%)$ and grain crops $(-0.55 \%)$. This is mainly due to trade diversion from Pakistan to CPTPP member countries, which are Pakistan's competitors in textile, wearing apparel like Vietnam, Malaysia.

Pakistan's proposed entry to CPTPP leads to a boost in Pakistan exports most notably in processed food (77\%), followed by WAP (41\%). Impact on the exports of textile (the top exports of Pakistan to the CPTPP region) is also positive and modest (33\%). CPTPP with Pakistan's inclusion may lead to increase in sectoral imports (particularly the imports of raw material and capital goods), which may in turn enhance domestic productive capacity, thereby leading to increase in sectoral exports. The other sectors, which also register an increase, include leather (11\%), extraction (10\%) and 'vegetable and fruit' (10.7\%). On the other hand, the exports of 'meat and livestock' and grain crops show decrease due to the extended CPTPP. Pakistan will face trade diversion due to

Table 4 Impact of CPTPP on sectorial output of Pakistan Source: Author's simulation

\begin{tabular}{lccc}
\hline Sectors & SIM-I [CPTPP(1 1)] & SIM-II [CPTPP(11)+ Pakistan] & $\begin{array}{l}\text { SIM-III } \\
\text { [CPTPP(11)+ Paki- } \\
\text { stan + USA] }\end{array}$ \\
& & & 0.205 \\
Grain Crops & -0.010 & 0.18 & 0.626 \\
Veg-Fruit & 0.100 & 0.77 & -0.481 \\
Meat \& Livestock & -0.01 & -0.47 & 0.97 \\
Extraction & 0.08 & 2.17 & 1.139 \\
Processed Food & -0.05 & 1.23 & -0.63 \\
Leather & -0.03 & -0.64 & 13.4 \\
Wearing Apparels (WAP) & -0.08 & 7.52 & 17.634 \\
Textile & -0.07 & 12.38 & -12.856 \\
Light Manufactures & 0.18 & -11.11 & 0.699 \\
Heavy Manufactures & 0.07 & 2.9 & \\
\hline
\end{tabular}


Table 5 Impact of CPTPP on sectorial exports of Pakistan Source: Author's simulation

\begin{tabular}{lrrc}
\hline Sectors & SIM-I [CPTPP(11)] & SIM-II [CPTPP(11) + Pakistan] & $\begin{array}{l}\text { SIM-III } \\
\text { [CPTPP(11)+ Paki- } \\
\text { stan + USA] }\end{array}$ \\
& & & -12.359 \\
Grain Crops & -0.550 & -7.880 & 10.793 \\
Veg-Fruit & 0.330 & 13.800 & -19.313 \\
Meat \& Livestock & -0.340 & -13.400 & 10.364 \\
Extraction & 0.420 & 13.310 & 67.456 \\
Processed Food & -0.420 & 77.950 & 11.014 \\
Leather & 0.120 & 19.740 & 73.904 \\
Wearing Apparels (WAP) & -0.350 & 41.380 & 33.572 \\
Textile & -0.080 & 25.590 & 19.607 \\
Light Manufactures & 0.180 & 31.570 & 20.636 \\
Heavy Manufactures & 0.430 & 29.740 & \\
\hline
\end{tabular}

entry to CPTPP as Australia and New Zealand might be the efficient suppliers of exports of these two commodities to the CPTPP members.

\subsection{Impact of CPTPP on sectoral imports of Pakistan}

Table 6 discusses the impact of various simulations on Pakistan's sectoral imports. CPTPP will lead to an overall decline in Pakistan's imports, while Pakistan's proposed entry to CPTPP (with and without USA) will significantly increases Pakistan imports of all tradable commodities. The modest increase in imports of Pakistan's top import sectors indicates that CPTPP may lead to worsening Pakistan's trade balance in the short run. In the long run, increase in imports may enhance domestic productive capacity. This may lead to increase in exports and so improvement in the trade balance.

\subsection{Impact of CPTPP on household income}

The discussion made so far has mainly focused on the impacts of trade policy on macroeconomic aggregates like GDP, terms of trade, output and trade flows. This research removes a single regional household in a standard GTAP model and replaces it with 16 representative households using MyGTAP model.

Table 7 reports the impact of CPTPP on the household income of Pakistan. Results show that real income of all the household would decrease due to the current CPTPP.

Table 6 Impact of CPTPP on sectorial imports of Pakistan Source: Author's simulation

\begin{tabular}{lccc}
\hline Sectors & SIM-I [CPTPP(1 1)] & SIM-II [CPTPP(11) + Pakistan] & $\begin{array}{l}\text { SIM-III } \\
\text { [CPTPP(11)+ Paki- } \\
\text { stan + USA] }\end{array}$ \\
& & & 32.739 \\
Grain Crops & -1.270 & 27.250 & 10.358 \\
Veg-Fruit & -0.620 & 9.000 & 28.446 \\
Meat \& Livestock & -1.430 & 19.880 & 0.529 \\
Extraction & -0.030 & 2.050 & 30.199 \\
Processed Food & 0.490 & 27.190 & 109.879 \\
Leather & -0.020 & 99.380 & 76.344 \\
Wearing Apparels (WAP) & -0.170 & 64.730 & 38.259 \\
Textile & -0.050 & 31.050 & 57.817 \\
Light Manufactures & -0.840 & 51.710 & 5.938 \\
Heavy Manufactures & -0.180 & 2.800 & \\
\hline
\end{tabular}


Table 7 Impact of CPTPP on household income Source: Author's simulation

\begin{tabular}{lllcc}
\hline $\begin{array}{l}\text { Household } \\
\text { codes }\end{array}$ & Household'types & $\begin{array}{l}\text { SIM-I } \\
\text { [CPTPP (11)] }\end{array}$ & $\begin{array}{l}\text { SIM-II [CPTPP } \\
\text { (11) Pakistan] }\end{array}$ & $\begin{array}{l}\text { SIM-III [CPTPP } \\
\text { (11) + Paki- } \\
\text { stan + USA] }\end{array}$ \\
\hline hhd-rs1 & Rural small farmer (quartile 1) & -0.01 & 10.86 & 11.120 \\
hhd-rs234 & Rural small farmer (quartile 234) & -0.03 & 11.13 & 11.336 \\
hhd-rm1 & Rural medium + farmer (quartile 1) & 0.17 & 15.07 & 11.864 \\
hhd-rm234 & Rural medium + farmer (quartile 234) & -0.02 & 14.40 & 12.497 \\
hhd-rl1 & Rural landless farmer (quartile 1) & -0.01 & 11.67 & 14.919 \\
hhd-rl234 & Rural landless farmer (quartile 234) & -0.04 & 10.26 & 12.090 \\
hhd-rw1 & Rural farm worker (quartile 1) & -0.04 & 4.08 & 11.069 \\
hhd-rw234 & Rural farm worker (quartile 234) & -0.09 & 1.46 & 4.490 \\
hhd-rn1 & Rural non-farm (quartile 1) & -0.14 & -3.34 & 2.476 \\
hhd-rn2 & Rural non-farm (quartile 2) & -0.15 & -3.58 & -1.674 \\
hhd-rn3 & Rural non-farm (quartile 3) & -0.15 & -3.71 & -1.826 \\
hhd-rn4 & Rural non-farm (quartile 4) & -0.16 & -3.79 & -1.917 \\
hhd-u1 & Urban (quartile 1) & -0.12 & -1.93 & -1.970 \\
hhd-u2 & Urban (quartile 2) & -0.14 & -2.99 & -0.462 \\
hhd-u3 & Urban (quartile 3) & -0.15 & -3.41 & -1.289 \\
Hhd-u4 & Urban (quantile 4) & -0.16 & -3.65 & -1.630 \\
\hline
\end{tabular}

Decrease in real income of farmers and farm workers is lower than non-farm and urban households. Simulations II and III lead to increase in exports, which would in turn lead to increase in real income of all household types linked with production of agricultural commodities. Highest increase is recorded by the rural medium farmer households (15.07\%) from Punjab. Pakistan exports are mainly consisted of agriculture goods. CPTPP with Pakistan's inclusion would mainly benefit the exports of textile and WAP, which in turn would be more beneficial for the labors and other factors engaged in the production of these goods. Overall household results show that small and medium farmers and even rural landless famers of Punjab and Sindh Province will benefit more as the real wages of these will increase more because these two provinces are the only cottongrowing provinces in Pakistan and their share in total cotton production are 80 and 20\%, respectively. Thus, better demand for labor, which mainly sprouts from cotton lint/yarn, textile and wearing apparel sectors, because of the improvement in output in these areas, results in better wages for labor workers involved in production of these goods.

\subsection{Impact of CPTPP on real factor rewards}

The latest Pakistan Social Accounting Matrix (SAM-2010-11) introduces many factors (labor, land and capital) to evaluate the impact of CPTPP on Pakistan economy. The SAM considers five categories of labor, i.e., small farmers, medium farmers, farm workers, nonfarm skilled and non-farm unskilled workers. Land includes land small, land medium and land large, whereas capital includes capital agriculture, formal capital and informal capital.

The result in Table 8 indicates that the impact on the factor rewards substantially differ across the types of factors and the nature of simulation. CPTPP will reduce the rewards of non-farm workers (skilled and unskilled) and capital (formal and informal). Trade diversion for Pakistan resulting from the implementation of the CPTPP would primarily affect the small-scale manufacturing sector, thereby leading to decline in employment of the factors and subsequent decrease in real factors' returns. Farmers, farm workers and land 
Table 8 Impact of TPP on real rewards Source: Author's simulation

\begin{tabular}{|c|c|c|c|c|}
\hline Factor codes & Factor description & SIM-I [CPTPP(11)] & $\begin{array}{l}\text { SIM-II } \\
\text { [CPTPP(11) + Paki- } \\
\text { stan] }\end{array}$ & $\begin{array}{l}\text { SIM-III } \\
{[\text { CPTPP }(11)+\text { Paki- }} \\
\text { stan + USA] }\end{array}$ \\
\hline flab-s & Labor-small farmer & 0.11 & 15.27 & 14.53 \\
\hline flab-m & Labor-medium + farmer & 0.08 & 15.03 & 14.36 \\
\hline flab-w & Labor-farm worker & 0.16 & 15.01 & 13.33 \\
\hline flab-l & Labor-non-farm low skilled & -0.05 & -1.94 & -1.10 \\
\hline flab-h & Labor-non-farm high skilled & -0.05 & -3.28 & -2.33 \\
\hline flnd-s & Land-large & 0.15 & 17.59 & 16.85 \\
\hline flnd-m & Land-medium & 0.12 & 17.63 & 16.93 \\
\hline flnd-I & Land-small & 0.08 & 17.67 & 17.03 \\
\hline Fliv & Livestock & 0.00 & 7.54 & 7.07 \\
\hline fcap-a & Capital-agriculture & 0.08 & 17.67 & 16.96 \\
\hline fcap-f & Capital-formal & -0.06 & -2.23 & -1.58 \\
\hline fcap-i & Capital-informal & -0.05 & -2.29 & -1.54 \\
\hline
\end{tabular}

would show no immediate response and so there is no meaningful impact of CPTPP on the rewards of these factors. Simulations II and III lead to a modest increase in returns of famers, farm workers, land and capital used in the agriculture sector. Highest increase is shown by small farmers (15.3\%), small land (17\%) and agriculture capital (16\%). This shows that small land and farmers would be the main beneficiaries of Pakistan's entry to CPTPP.

\subsection{Effect on overall Income inequality in Pakistan}

The CGE framework can be considered as an ideal tool in analyzing trade and poverty linkage within developing countries. As discussed in methodology, there are quite a few methods to measure inequality. We use the most popular inequality measure known as Gini coefficient to see the impact of TPP on household inequality in Pakistan. Moreover, due to the limitation of our data, we only capture the inequality between household groups.

The range of the Gini index is between 0 and 1 ( 0 and 100\%), where 0 indicates perfect equality and $1(100 \%)$ indicates maximum inequality. The closer a Gini coefficient to 1 , the more unequal is the expenditure distribution. The Gini index is the most frequently used inequality index. The reason for its popularity is that it is easy to compute as a ratio of two areas in Lorenz curve diagrams.

Table 9 shows the impact of all research simulation used in this study on overall income inequality in Pakistan. All simulation will have a positive impact on income inequality in Pakistan. Pakistan's inclusion in CPTPP will reduce the gap between highincome and low-income households in Pakistan. This in turns may lead to decrease in the overall income inequality in the country.

\section{Conclusion and policy recommendation}

The current study examined the implications of Comprehensive and Progressive Agreement for Trans-Pacific Trade Partnership (CPTPP) on Pakistan's economy. An analytical framework was developed, in which MyGTAP model, which is an extension of standard GTAP model, was linked to a representative household model using the latest available comprehensive Social Accounting Matrix (SAM) 2010-11 to capture the impacts of TPP on GDP growth, real factor wages and income distribution. 
Table 9 Impact on Income Inequality in Pakistan Source: Author's simulations

\begin{tabular}{ll}
\hline CPTPP scenarios & Gini coefficient \\
\hline Base Index & 0.41592 \\
CPTPP $(11)$ & 0.41591 \\
CPTPP $(11+$ Pak $)$ & 0.39558 \\
CPTPP $(11+$ USA + Pak) & 0.39842
\end{tabular}

One of the first conclusions we infer from the analysis is that the current CPTPP will have an adverse impact on Pakistan economy. This is primarily due to alteration in the global supply chain of textile and apparels and the trade diversion of Textile and wearing apparels in favor of the CPTPP members. The negative impact is observed across all macroeconomic variables such as real GDP, sectoral export and imports and the real household income of almost all representative household types used in this study. However, Pakistan's proposed entry to CPTPP shows an overall positive impact on Pakistan economy as well as household income.

Second, on household level, it is pragmatic from results that small and medium farmers and even rural landless famers of Punjab and Sindh Province will benefit more as the real wages of these will increase more because these two provinces are the only cottongrowing provinces in Pakistan and their share in total cotton production is 80 and 20\%, respectively. Thus, better demand for labor, which mainly sprouts from cotton lint/yarn, textile and wearing apparel sectors, because of the improvement in output in these areas, results in better wages for labor workers involved in production of these goods.

Last but not the least, the most notable increase in the household income of small and rural landless farmers will have a positive impact on overall income inequality in Pakistan. Hence, CPTPP, with Pakistan, will reduce the gap between rich and poor in Pakistan. Thus, this study recommends the government of Pakistan to negotiate Pakistan's inclusion into the CPTPP.

Authors' contributions

All authors have equally contributed to designing of the research, the process of data collection and calculation as well as drafting and revision of the manuscript. All authors read and approved the final manuscript.

Earlier version of the paper was presented at the 24th IIOA Conference held at Yonsei University, Seoul, South Korea, during July 4-8, 2016.

This paper is also part of a Ph.D. Thesis of Naseeb Zada, School of Economics, Quaid e Azam University, Islamabad.

Author details

${ }^{1}$ Department of Economics, COMSATS Institute of Information Technology (CIIT), Islamabad, Pakistan. ${ }^{2}$ WTO Chair Program, Department of Natural Resource Economics, Sultan Qaboos University, Muscat, Oman. ${ }^{3}$ Quaid-I-Azam University Islamabad, Islamabad, Pakistan. ${ }^{4}$ Gokhale Institute of Politics and Economics, Pune, India. ${ }^{5}$ Department of Natural Resource Sciences, Agricultural Economics Program, McGill University, Montreal, QC, Canada.

Acknowledgements

None.

Competing interests

The authors declare that they have no competing interests.

Availability of data and materials

The dataset supporting the conclusions of this article is available in and bought from the GTAP database version 9 and Social Accounting Matrix of Pakistan 2010-11.

Consent for publication

Not applicable. 
Ethics approval and consent to participate

Not applicable.

Appendix 1: Regional aggregation used in the study

\begin{tabular}{|c|c|}
\hline Region & Description \\
\hline Pakistan & Pakistan \\
\hline China & China \\
\hline India & India \\
\hline USA & USA \\
\hline Bangladesh & Bangladesh \\
\hline Sri Lanka & Sri Lanka \\
\hline Indonesia & Indonesia \\
\hline Malaysia & Malaysia \\
\hline Singapore & Singapore \\
\hline Thailand & Thailand \\
\hline Turkey & Turkey \\
\hline Australia & Australia \\
\hline New Zealand & New Zealand \\
\hline Japan & Japan \\
\hline Korea & Korea \\
\hline Chile & Chile \\
\hline Canada & Canada \\
\hline Peru & Peru \\
\hline Iran & Iran \\
\hline Brunei & Brunei \\
\hline S. Arab & S. Arab \\
\hline UAE & United Arab Emirates \\
\hline Vietnam & Vietnam \\
\hline Mexico & Mexico \\
\hline Egypt & Egypt \\
\hline Rest of S. Asian & Rest of South Asia \\
\hline Other OECD & Australia, New Zealand, Japan, Korea, Canada, Mexico, Chile \\
\hline Europe 27 & $\begin{array}{l}\text { Austria, Belgium, Cyprus, Czech Rep, Denmark, Estonia, Finland, France, Ger- } \\
\text { many, Greece, Hungary, Ireland, Italy, Latvia, Lithuania, Luxembourg, Malta, } \\
\text { Netherlands, Poland, Portugal, Slovakia, Slovenia, Spain, Sweden, Norway, } \\
\text { Rest of EFTA, Turkey, Albania, Bulgaria, Belarus, Croatia, Romania, Ukraine, } \\
\text { Rest of Eastern Europe, Rest of Europe }\end{array}$ \\
\hline Rest of Asia & $\begin{array}{l}\text { Hong Kong, Taiwan, Rest of East Asia, Cambodia, Lao People's Democratic } \\
\text { Republic, Philippines, Rest of Southeast Asia }\end{array}$ \\
\hline Rest of World & $\begin{array}{l}\text { Morocco, Tunisia, Bahrain, Argentina, Colombia, Ecuador, Paraguay, Uruguay, } \\
\text { Venezuela, Rest of South America, Cost Rica, Guatemala, Nicaragua, Panama, } \\
\text { Rest of Central America, Caribbean, Israel, Kuwait, Oman, Qatar, Rest of North } \\
\text { Africa, Cameroon, Cote d'Ivoire, Ghana, Nigeria, Senegal, Rest of Western } \\
\text { Africa, Central Africa, South Central Africa, Ethiopia, Kenya, Madagascar, } \\
\text { Malawi, Mauritius, Mozambique, Tanzania, Uganda, Zambia, Zimbabwe, } \\
\text { Rest of Eastern Africa, Botswana, Namibia, South Africa, Rest of South Africa } \\
\text { Customs Union, Rest of North America, Rest of the World }\end{array}$ \\
\hline
\end{tabular}


Appendix 2: Sectors aggregation used in the study

\begin{tabular}{ll}
\hline Code & Comprising GTAP sectors (code) \\
\hline GrainCrops & Pdr, wht, gro,osd, c_b, pfb, ocr, pcr \\
VegFruit & V_f \\
MeatLvtk & Ctl, oap, rmk, wol, cmt, omt \\
Extraction & Frs, fsh, coa, oil, gas, omn \\
Processed Food & Vol, mil, sgr, ofd, b_t \\
leather & Lea \\
Wap & Wap \\
Textile & Tex \\
LightMnfc & Lum, ppp, fmp, mvh, otn, omf \\
HeavyMnfc & P_c, crp, nmm, i_s, nfm, ele, ome \\
Util_Cons & Ely, gdt, w \\
TransComm & Trd, otp, wtp, atp, cmn \\
FinServices & of, isr \\
BusServices & Obs \\
OthServices & Ros, osg, dwe \\
\hline
\end{tabular}

\section{Appendix 3: Factor types used in this study}

\begin{tabular}{ll}
\hline Pakistan SAM & \\
\hline Code & Description \\
\hline flab-s & Labor-small farmer \\
flab-m & Labor-medium + farmer \\
flab-w & Labor-farm worker \\
flab-l & Labor-non-farm low skilled \\
flab-h & Labor-non-farm high skilled \\
flnd-s & Land-large \\
flnd-m & Land-medium \\
flnd-l & Land-small \\
fliv & Livestock \\
fcap-a & Capital-agriculture \\
fcap-f & Capital-formal \\
fcap-i & Capital-informal \\
\hline
\end{tabular}




\section{Appendix 4: Household types used in the study}

\begin{tabular}{|c|c|c|c|c|}
\hline & Household types & HH code & Population (million) & Income (billion) \\
\hline 1 & $\begin{array}{l}\text { Rural small farmer } \\
\quad \text { (quartile 1) }\end{array}$ & hhd-rs1 & 4193 & 275.6327 \\
\hline 2 & $\begin{array}{l}\text { Rural small farmer } \\
\text { (quartile 234) }\end{array}$ & hhd-rs234 & 15,565 & 2232.853 \\
\hline 3 & $\begin{array}{l}\text { Rural } \\
\text { medium + farmer } \\
\quad \text { (quartile 1) }\end{array}$ & hhd-rm1 & 208 & $14.13,264$ \\
\hline 4 & $\begin{array}{l}\text { Rural } \\
\text { medium + farmer } \\
\text { (quartile 234) }\end{array}$ & hhd-rm234 & 2914 & 853.3687 \\
\hline 5 & $\begin{array}{l}\text { Rural landless farmer } \\
\text { (quartile 1) }\end{array}$ & hhd-rl1 & 3348 & 194.3888 \\
\hline 6 & $\begin{array}{l}\text { Rural landless farmer } \\
\text { (quartile 234) }\end{array}$ & hhd-rl234 & 7292 & 947.8456 \\
\hline 7 & $\begin{array}{l}\text { Rural farm worker } \\
\text { (quartile 1) }\end{array}$ & hhd-rw1 & 6333 & 238.9349 \\
\hline 8 & $\begin{array}{l}\text { Rural farm worker } \\
\text { (quartile 234) }\end{array}$ & hhd-rw234 & 8305 & 722.2187 \\
\hline 9 & $\begin{array}{l}\text { Rural non-farm (quar- } \\
\text { tile 1) }\end{array}$ & hhd-rn1 & 12,595 & 481.5706 \\
\hline 10 & $\begin{array}{l}\text { Rural non-farm (quar- } \\
\text { tile 2) }\end{array}$ & hhd-rn2 & 10,888 & 645.3767 \\
\hline 11 & $\begin{array}{l}\text { Rural non-farm (quar- } \\
\text { tile 3) }\end{array}$ & hhd-rn3 & 9088 & 849.5021 \\
\hline 12 & $\begin{array}{l}\text { Rural non-farm (quar- } \\
\text { tile 4) }\end{array}$ & hhd-rn4 & 6316 & 1388.453 \\
\hline 13 & Urban (quartile 1) & hhd-u1 & 5930 & 271.7564 \\
\hline 14 & Urban (quartile 2) & hhd-u2 & 8820 & 657.4251 \\
\hline 15 & Urban (quartile 3) & hhd-u3 & 11,506 & 1366.653 \\
\hline 16 & Urban (quartile 4) & hhd-u4 & 17,080 & 6979.068 \\
\hline \multicolumn{5}{|c|}{ All households } \\
\hline
\end{tabular}

Source: Pakistan Social Accounting Matrix (SAM) 2010-11; Household Income and Expenditure Survey (HIES) 2011

\section{Appendix 5: Elasticities used in MyGTAP model}

The standard GTAP model includes a non-standard constant difference of elasticity (CDE) expenditure function. The advantage of a CDE function is that it models well a variety of consumption patterns found at differing income levels. That is to say it generates classical 'Engels' curves which are characterized by shifting consumption between necessities and luxury goods (Walmsley and Minor 2013). While the CDE provides a good basis for modeling private consumption across a broad range of households and countries, it is not ideal for modeling extreme situations, where poverty and subsistence expenditures are dominant. Subsistence expenditures are defined as a share of expenditure being tied to a specific consumption bundle, which must be consumed no matter what changes in prices and incomes may arise in the simulation (Minor and Mureverwi 2013).

\section{Private household expenditure}

The MyGTAP model developed by (Walmsley and Minor 2013) is not based on an elasticity system to govern the household behavior in expenditure. Both CDE and LES can 
be used with the model per requirements. The household expenditure is separated into expenditure consumption and saving. The user defines the use of CDE or LES through a binary parameter (PRIVTYPE) which is read in from the GTAPPARM file (default.prm). In the MyGTAP data program (Walmsley and Minor 2013), special country takes the LES value as 1 and 0 for all other countries. ${ }^{3}$ The total private consumption expenditure $(y p h(h, r))$ is determined by a Cobb-Douglas function as private household income is allocated across private consumption and household savings in a similar way to which it is determined in the standard GTAP model albeit at household level (Walmsley and Minor 2013) .

\section{CDE}

In MyGTAP Model, the traditional CDE equation in the standard GTAP model applies with two important differences (Eq. 2). First, the equation only applies to the subset of regions REG_CDE; and second, household private expenditure $(\mathrm{yph}(\mathrm{h}, \mathrm{r}))$ is being allocated across commodities not total private expenditure of the regional household $(\mathrm{yp}(\mathrm{r})$ in standard GTAP.

$$
\begin{aligned}
\mathrm{qph}(\mathrm{i}, \mathrm{h}, \mathrm{r})-\operatorname{poph}(\mathrm{h}, \mathrm{r})= & \operatorname{sum}\left(\mathrm{k}, \mathrm{TRAD} \_C O M M, E P(\mathrm{i}, \mathrm{k}, \mathrm{h}, \mathrm{r}) * \operatorname{pph}(\mathrm{k}, \mathrm{h}, \mathrm{r})\right) \\
& +\mathrm{EY}(\mathrm{i}, \mathrm{h}, \mathrm{r}) *[\operatorname{yph}(\mathrm{h}, \mathrm{r})-\operatorname{poph}(\mathrm{h}, \mathrm{r})]
\end{aligned}
$$

\section{Linear expenditure system (LES)}

The code used to incorporate LES for the REG_LES subset of countries is adapted from the Orani model, which was developed by Dixon, Parmenter, Sutton and Vincent (1982).

First two parameters must be added to the MyGTAP model tab file:

1. The Frisch LES 'parameter' (FRISCH(h,r)) is calibrated from the income elasticity and household consumption shares ${ }^{4}$ or read in from the parameters file.

2. Household expenditure elasticities (EPS(i,h,r)) are set equal to the income elasticities also used in the $\mathrm{CDE}$ or read in from the parameters file.

These parameters can then be used to determine the average and marginal share of luxury goods in total expenditure. With the share of luxury goods in total expenditure and consumption is then a matter of determining how this income will be divided across subsistence ((qph_sub(i,h,r))) and luxury (qph_lux(i,h,r)) consumption. Total consumption $(\mathrm{qph}(\mathrm{i}, \mathrm{h}, \mathrm{r}))$ then depends on the sum of these two demands for subsistence and luxury commodities. Following the LES methodology, subsistence consumption (qph_ $\operatorname{sub}(\mathrm{i}, \mathrm{h}, \mathrm{r}))$ remains constant and only changes with changes in the population or number of households (poph(h,r)) and any taste changes (asub(i,h,r)). Consumption of luxury commodities (qph_lux $(\mathrm{i}, \mathrm{h}, \mathrm{r})$ ) then depends on private expenditure left over for luxury consumption (yph_lux(h,r)), prices (pph(i,h,r)) and a taste parameter (alux(i,h,r).

\footnotetext{
3 This is similar to the parameter SLUG which is used for determining sluggish verses mobile endowments (Minor and Walmsley 2012b).

${ }^{4}$ Calibration equations used are based on those taken from the CRUSOE suite developed by Mark Horridge. http:// www.monash.edu.au/policy/crusoe.htm and Minor and Welmsley (2012b) also include an assertion that all FRISCH parameters are less than - 1.8 for REG_LES countries.
} 


\section{Armingtons}

The implementation region-specific Armingtons elasticity's is used. First, ESUBD_R, the standard GTAP region-generic elasticity, is defined and read into the model from the GTAP database. Next, a region-specific elasticity is defined. This is initially set equal to the region-generic, unless an additional header exists (ifheaderexists), 'ESDR' containing region-specific details (Walmsley and Minor 2013).

\section{Coefficient (parameter)(all,i,TRAD_COMM)}

ESUBD_R(i)

\# region- generic el. of sub. domestic/imported for all agents \#;

Read

ESUBD_R from file GTAPPARM header "ESBD";

Coefficient (all,i,TRAD_COMM)(all,r,REG)

ESUBD(i,r) \# region- specific el. of sub. among imports of $\mathrm{i}$ in Armington structure \#;

Formula (all,i,TRAD_COMM)(all,r,REG)

$\operatorname{ESUBD}(\mathrm{i}, \mathrm{r})=\operatorname{ESUBD} \mathrm{R}(\mathrm{i})$;

Read (ifheaderexists)

ESUBD from file GTAPPARM header "ESDR";

\section{Publisher's Note}

Springer Nature remains neutral with regard to jurisdictional claims in published maps and institutional affiliations.

Received: 6 May 2017 Accepted: 6 November 2017

Published online: 10 January 2018

\section{References}

Aguiar A, Narayanan B, McDougall R (2016) An overview of the GTAP 9 data base. J Glob Econ Anal 1(1):181-208

Areerat T, Kameyama H, Ito S, Yamauchi K-E (2012) Trans Pacific stategic economic partnership with Japan, South Korea and China Integrate: general equilibrium approach. Am J Econ Bus Adm 4(1):40

Bandara JS (1991) Computable general equilibrium models for development policy analysis in LDCs. J Econ Surv $5(1): 3-69$

Banga R (2014) Trans-pacific partnership agreement (TPPA): implications for malaysia's domestic value-added trade. UNCTAD background paper

Blake A (1998) Computable general equilibrium modelling and the evaluation of agricultural policy. University of Nottingham, Nottingham

Cabinet Secretariat J (2015) Study of the economic impacts of the TPP

Cheong I, Tongzon J (2013) Comparing the economic impact of the Trans-Pacific Partnership and the regional comprehensive economic partnership. Asian Econ Papers 12(2):144-164

Ciuriak D, Xiao J (2014) The trans-pacific partnership: evaluating the'landing zone'for negotiations

Cororaton CB, Orden D (2015) Potential economic effects on the philippines of the trans-pacific partnership (TPP): GII working paper

Disdier AC, Emlinger C, Fouré J (2016) Interdependencies between Atlantic and Pacific agreements: evidence from agrifood sectors. Econ Model 55:241-253

Durongkaveroj W (2015) The next chapter of ASEAN economic community through integrating with the existing FTA partners (RCEP), Turkey, and Pakistan: University Library of Munich, Germany

Fergusson IF, McMinimy MA, Williams BR (2015) The trans-pacific partnership (TPP): in brief

Ganesh-Kumar A, Chatterjee T (2016) Mega external preferential trade agreements and their impacts on indian economy. Foreign Trade Rev 51(1):46-80

Gilbert JP, Furusawa T, Scollay RD (2016) The economic impact of Trans-Pacific partnership: what have we learned from CGE simulation?: ARTNeT working paper series 
Harrison GW, Humphrey SJ, Verschoor A (2010) Choice under uncertainty: evidence from Ethiopia, India and Uganda. Econ J 120(543):80-104

Kagatsume MaMT (2012) Business activities by Japanese food and agricultural companies and Trans-Pacific partnership negotiation on Japanese agriculture: an approach by the regional dynamic computable general equilibrium model Seibutsu Shigen Keizai Kenkyu 127-165 (in Japanese)

Kehoe PJ, Kehoe TJ (1994) A primer on static applied general equilibrium models. Federal Reserve Bank Minneap Q RevFederal Reserve Bank Minneap 18(2):2

Li C, Whalley J (2014) China and the Trans-Pacific Partnership: a numerical simulation assessment of the effects involved. World Econ 37(2):169-192

Li X, Yao Y (2014) Asia-Pacific integration within a broader Trans-Pacific Partnership agreement. China Econ J 7(2):221-236 Litchfield JA (1999) Inequality: methods and tools. World Bank 4

Lu S (2015) Impact of the Trans-Pacific Partnership on China's textiles and apparel exports: a quantitative analysis. Int Trade J 29(1):19-38

McDougall R (1995) Computable general equilibrium modelling: introduction and overview. Asia Pac Econ Rev 1(1):88-91

Narayanan B, Sharma SK (2016) An analysis of tariff reductions in the Trans-Pacific Partnership (TPP): implications for the Indian economy. Margin J Appl Econ Res 10(1):1-34

Oduncu A, Mavuş M, Güneş D (2014) The possible effects of Trans-Pacific Partnership on Turkish economy

Petri PA, Plummer MG (2016) The economic effects of the Trans-Pacific Partnership: new estimates

Petri PA, Plummer MG, Zhai F (2012) The Trans-pacific partnership and Asia-pacific integration: a quantitative assessment, vol 98. Peterson Institute, Washington

Rahman MM, Ara LA (2015) TPP, TTIP and RCEP: implications for South Asian economies. South Asia Econ J 16(1):27-45

Savard L (2003) Poverty and income distribution in a CGE-household micro-simulation model: top-down/bottom up approach

Shaikh F, Syed AASG, Shah H, Shah AA (2012). Observing Impact of SAFTA on Pakistan's economy by using CGE model. Pak J Commer Soc Sci 6(1)

Strutt A, Minor P, Rae AN (2015) A dynamic computable general equilibrium (CGE) analysis of the Trans-Pacific Partnership agreement: potential impacts on the New Zealand economy. Ministry of Foreign Affairs and Trade, Wellington

Takamasu AaJX (2012) The effects of the TPP on agricultural production in Japan and China: a computer simulation analysis using the GTAP model Kansai Daigaku Shakaigakubu Kiyou 1-32 (in Japanese)

Thorstensen V, Ferraz L (2014) The impacts of TTIP and TPP on Brazil. Fundação Getúlio Vargas, Rio de Janeiro

USITC (2016) Trans-Pacific partnership agreement: likely impact on the US economy and on specific industry sectors. Publication Number 4607

Walmsley T, Minor P (2013) MyGTAP model: a model for employing data from the MyGTAP data application — multiple households, Split Factors, Remittances, Foreign Aid and Transfers.

Winters LA, McCulloch N, McKay A (2004) Trade liberalization and poverty: the evidence so far. J Econ Liter 42(1):72-115

\section{Submit your manuscript to a SpringerOpen ${ }^{\circ}$ journal and benefit from:}

- Convenient online submission

- Rigorous peer review

- Open access: articles freely available online

- High visibility within the field

- Retaining the copyright to your article

Submit your next manuscript at $\boldsymbol{s p r i n g e r o p e n . c o m ~}$ 